The Consumer Project on Technology ${ }^{1}$ ( CPTech) Initial Comments to the Gowers Review of Intellectual Property Law in the UK.

21 April 2006

\title{
General questions
}

Question f ) How well does UK IP system promote innovation?

\section{Patents}

In areas where it is appropriate and managed properly, if the benefits outweigh the costs and are superior to alternative mechanisms, the patent system can play a positive role in stimulating innovation, and enhancing economic growth and improved quality of life for the benefit of all in society.

The challenge is to design a patent system that does not present excessive costs on society, through for example unreasonable restrictions on access to new inventions, or harm to other non-patent systems that would otherwise stimulate inventive activity.

The patent system is only used in certain areas of the economy. Some types of inventive activity are not subject to patents, and some types of research and development do not benefit from patent protection. The limited role for the patent system is deliberate, and recognizes the importance of other mechanisms, incentives, rewards, tendencies, and forces in the process of innovation and progress in the arts and sciences.

The patent system co-exists with a wide range of other public policy instruments, including regulation, government procurement, taxation, public subsidies, and nonpatent intellectual property regimes, which also play a role in innovation and progress in the arts and sciences. For policy makers, the patent system does not have the weight of the world on its shoulders -- it is part of a larger eco-system that supports innovation.

The patent system should be reviewed, as the outline paper makes clear, there are already concerns about the operation of the present system both in the UK and in the US.

It is extremely costly to manage the patent system, in terms of (1) evaluating pre and post grant disputes over the validity and relevance of patents, (2) negotiating the rights to use patented inventions, and (3) reducing the utilization of patented inventions.

If patents were costless, they would not be controversial. But they do present costs to society, and in some cases, unacceptable costs. These include excessive prices for certain patentable inventions (such as Herceptin, the high priced and often rationed cancer drug, the high priced breast cancer screening tests protected by the

\footnotetext{
${ }^{1}$ CPTech is a NGO, with offices in London, Geneva and Washington DC. Currently much of our work concerns intellectual property policy and practices, focusing on access to knowledge. CPTech also studies different approaches to the production of knowledge goods, including new business models that support creative individuals and communities. Full details can be found on our website www.CPTech.org. We are also a member of the Transatlantic Consumer Dialogue (www.tacd.org).
} 
BRCA1/BRCA2 patents,), restrictions on the supply or inability to meet the demands of the market (such as Tamiflu), inadequate government stockpiles of important medicines), patent thickets that make it difficult to adopt standards for new technologies in the areas of computing and telecommunication devices, and many other areas.

A good patent system recognizes and addresses the issues of costs and benefits, by limiting the use of the patent system only to those areas where the benefits outweigh the costs, and secondly, by limiting the rights associated with a patent, in order to address well known problems. Of course, this is what we expect out of any other system of government intervention in the economy, such as programmes that address health, safety or environmental protection. But it is sometimes obscured in the areas of patent policy, by the framing of patents as "intellectual property rights," making it seem as if a patent is something an inventor has a natural right to.

The Review should acknowledge the limited role for patents in the economy, and develop a better understanding how to set appropriate limits. For example, why would the UK extend patents to a field where the benefits outweigh the costs? Is it because no one is comparing the costs to the benefits? Are the benefits to be taken on faith only, and the costs to be ignored? Do we "count" only the benefits that accrue to the right owner, but not the costs that are imposed on society? Are these only problems of measurement, or is there a bias in favour of highly organized right-owner interests?

There are areas where the evidence suggests patents should not be used. These include for example: (1) business practices, where innovation is extensive without patent protection and there is a bad record of low patent quality in countries that issue such patents, (2) software, where innovation is often threatened by patent protection, innovations are not formally documented in academic or technical literature leading to very low patent quality, where the complex nature of major software programs makes it essentially impossible to develop new programs that do not infringe patents, and where software benefits from a host of other protections, including copyright, trade secret protection and contracts, (3) certain areas in medicines where the patent system is an unneeded and unwelcome barrier to the use of innovations, such as recommended doses of medicines or surgical procedures on humans, to mention only a few areas.

When the patent system is used, there must be a robust and effective mechanism to address abuses, and the public interest in more liberal use of the inventions. The limitations and exceptions to rights must include public authority to authorize both remunerative and non-remuneration non-voluntary uses of inventions, and to place constructive obligations on patent owners.

The Review should look at developing new approaches to ensure greater public benefits, whilst rewarding inventors. For example, a greater reliance upon remunerative rather than exclusive rights would strike a different and many say better balance between the need to provide incentives for investments in invention, and the benefits of broader access to inventions. One example of this is the EU Directive on 
the Legal Protection of Biotechnological Inventions, ${ }^{2}$ which in Article 12, sets out mandatory cross licensing of patents in cases where there is another invention or a new seed variety that provides a "significant technical progress of considerable economic interest."

The UK should consider extending this approach to other areas where the patent system could be managed as a liability rule, rather than as an exclusive right. This would ensure that patents and patent thickets do not block follow-on research.

The major barrier for greater adoption of liability rules (a right to use, subject to remuneration) for patents is a perception that it is difficult for governments or arbitrators to determine the appropriate amount of remuneration. But there may be considerable advantages to abandoning the "willing buyer willing seller" approach, at least in some areas were the valuation problem is manageable. For example, in looking at market outcomes from patent pools in areas of standards, such as the patents on consumer electronics technologies, it seems clear that single digit royalties payable to patent pools are considered reasonable. Bargaining could be reduced by simply providing a compulsory license on a pool of patents that was capped at a reasonable figure, such as 1,2,4 or 6 percent of sales of the devices or services, depending upon standard practices in the relevant industry.

Some researchers think this concept could also be extended into areas of research tools for new medicines, where the use of any tool would be authorized in return for a reasonable reach-through royalty against the new product.

In any of these cases, parties could voluntarily negotiate lower royalties, much like the case today involving negotiations over the use of copyrighted songs that are subject to statutory licensing.

\section{Copyright}

We believe that the starting point for policy maker should be how best can we create a knowledge economy and increase access to that knowledge. Copyright is one method but not the only one to encourage the creation and dissemination of knowledge.

The debate on copyright has been dominated by discussions about music and movies, however the same rules apply to books, libraries, educational needs and access for consumers with disabilities. The on going expansion of copyright law, as well as the way exclusive rights in content are exercised, threatens access to knowledge in many ways.

Uncritical expansions of copyright lead to the greater privatization of knowledge, and a shrinking of the public domain. The push for every greater copyright protection appears to have been motivated by an uncritical belief that the enclosure of knowledge is the best way to promote creativity, invention and development. CPTech believes this older way of looking at things is wrong, and outdated. The great success of the Internet, which is based upon public domain technologies, the free software and

\footnotetext{
${ }^{2}$ Directive 98/44/EC of The European Parliament and of the Council, of 6 July 1998, on The Legal Protection Of Biotechnological Inventions, Article 12.
} 
open access publishing movements, and projects like the Human Genome Project illustrate how useful it is share knowledge goods widely.

We are learning not only the value and importance of the pure public domain, where knowledge is not owned by anyone, but also, the value of the other elements of the knowledge commons, where the private owners of knowledge goods make them freely available to everyone --like the Wikipedia, much of the free software licensed under the GNU General Public License for free software, or the Creative Commons, to mention just a few examples. It is important therefore that the Review considers the possibility of new incentives to create and contribute works to the knowledge commons. The Review should also avoid restrictive intellectual property rules and systems that create unnecessary barriers to the development of these important new approaches.

The Review should also consider the way in which the UK feeds into and consults on, International Agreements that seek to expand rights. There is little parliamentary scrutiny of decisions by relevant bodies overseas in particular the World Intellectual Property Organisation. Treaties agreed at WIPO often undergo little scrutiny by the public or industries more broadly affected, yet harmonise new rights on a Europe wide basis, with little ability for either the EU or national parliaments to amend in any detail.

While the Patent office does seek to consult, greater efforts are needed to connect with broader communities who may be affected for the first time. An example of this is the current proposal for a new Treaty on Broadcasting and Webcasting, currently under discussion at WIPO. One of the most contentious issues is the proposal for a new layer of rights to be granted to works distributed on the Internet, that would supplement copyright, and expand dramatically the problems associating with obtaining permissions to use works, and set a troubling new precedent that would restrict the horizontal distribution of works on the Internet. ${ }^{3}$

Many technology leaders ${ }^{4}$, who consider that copyright is a sufficient tool to protect creative works have opposed the proposal, and stated that any effort to create a new layer of IPR based upon transmissions of information would increase the costs of transactions to obtain permissions to use and reuse works. Copyright-holders, leading academic scholars, as well as consumer groups and other civil society NGOs have also expressed opposition to the treaty ${ }^{5}$

After first opposing this webcasting proposal, the European Commission, with no public consultation, appears to be now supporting it. The webcasting treaty proposal will be profoundly harmful to the public, and will certainly have many unforeseen impacts on new innovative services and technologies, including those that are being stimulated by the falling costs of creating and distributing audio visual works,

\footnotetext{
${ }^{3}$ (For more information see. "Document prepared by the Chair of the Standing Committee on Copyright and Related Rights. Working Paper on Alternative and Non-Mandatory Solutions on the Protection in Relation to Webcasting. SCCR/12/5," http://www.CPTech.org/ip/wipo/wipo04132005.doc)

${ }^{4} 4$ (See http://www.eff.org/IP/WIPO/?f=20041117 open letter.html

${ }^{5}$ (See: http://www.CPTech.org/ip/wipo/bt/bt-signon.html, http://news.ft.com/cms/s/441306be-2eb611da-9aed-00000e2511c8.html, and rights holders (see http://www.CPTech.org/ip/wipo/bt/rightholder-quotes.html
} 
including also the streaming of public events and meetings of all kinds, and the new multiparty collaborations to create works that do not fit neatly into older notions of authorship. Consider, for example, IBM's vision of grid computing. ${ }^{6}$

The imposition of a new layer of formalities, and the attempt to claim ownership over copyright free or freely licensed works will have negative consequences on the entire Internet Community, who are largely unaware of these discussions. The proposal is due to be discussed at WIPO again in May 2006 and badly needs political and wider industry scrutiny.

The Review should also consider the proposals contained in the Access to Knowledge Treaty drafted by a broad array of international experts, industry stakeholders and government officials from the North and South, which sets out proposals for many of the issues covered by this review. ${ }^{7}$

\section{Specific questions}

\section{Current term of protection on sound recordings and performers rights}

We support the principles of the Adelphi Charter that the presumption should be against extended the copyright terms and if requested the onus should be on those making the request to justify it. There has been too little scrutiny of the adverse effects of the continual extension of the copyright term on access to the public domain.

Government officials often find it difficult to assign values to something that has a price of zero. Some copyright owners assert that their private losses from infringement of works can be measured by estimating the number of unauthorized uses of a work, multipilied by prices of legitimate copies, an approach that is of course flawed, because it over-estimates the value of the works to the user. However, it can be useful starting point for thinking about the value to society of broader access to a work that enters the public domain.

There can be no serious thought that the current 50 years of right are an inadequate incentive for performers to record music. Increased revenue to the copyright-owner will be more than off-set by a combination of the higher prices to consumers, and the economic deadweight losses from works that underutilized because of the high prices, or the failures of the copyright owners to distribute works.

Arguments for extension that are based on the "fairness" of providing parity with author's rights, leave out the unfair result of higher prices on consumers, and leave also unexamined the fairness of the ownership of older performer rights. Often it is the case that the beneficiaries of the extended rights will be publishers, rather than the artists themselves.

If the Review actually seeks to address the term extension in terms of "fairness," it should consider some provisions that would limit the benefits of the extension to the

\footnotetext{
${ }^{6} \mathrm{http}: / / \mathrm{www}-1 . i b m . c o m / g r i d /$ about_grid/what_is.shtml

${ }^{7} \mathrm{http}: / / \mathrm{www} . \mathrm{cptech} .0 \mathrm{rg} / \mathrm{a} 2 \mathrm{k} / \mathrm{consolidatedtext-may} 9 . \mathrm{pdf}$
} 
artists themselves, or perhaps to those artists who are most in need. This is of course about money, and the money is going to come from consumers. What is the compelling reason to transfer wealth from consumers to persons who have already held an exclusive right for 50 years?

Certainly in the cases where the performers have effectively alienated their rights to works, through contracts, there should be no extension of the rights, unless of course, this is really about enriching publishers at the expense of consumers.

The extension of existing copyright terms allows publishers to make money from old works, stifling the incentive to support the creation of new works, which is the purpose of copyright. In addition as it is a blanket extension i.e applies to all works it keeps vast amounts of material out of the public domain in order to protect a small minority of successful copyrights. The vast majority of this work will no longer be commercially available. 'That means no-one is making money from it, but it is virtually impossible to find (and illegal to re-use creatively), , because it remains copyrighted, protected for no reason, to no-one's benefit. ${ }^{8}$

We believe that the Review should consider the suggestions of the the Open Knowledge Foundation, for the reintroduction of registration. The copyright register would be a simple directory for those seeking permission to re-use copyrighted material (currently often an arduous if not impossible task). This would also help the problem of Orphan works. An additional possibility that would have zero impact on the remuneration of artists would be to divide current copyright into two terms, with renewal of the second term dependant upon payment of a nominal fee. This would ensure that all work without commercial value would automatically pass into the public domain.

We also support calls for creators to impliment a 'use it or lose it' obligation on rightsholders. So for example if a record company holds the copyright in a performance or song but fails to commercially expliot it during the copyright term, the rights would revert to the orginal creator.

\section{Copyright- Digital rights Management}

Much of the discussion on the digital environment has focused on the perspective of rights holders, fighting copyright infringement and respecting copyright laws. We believe that, to date, policymakers have failed to properly view the purpose and benefit of DRMs from the consumer perspective, and there has been little analysis of the long-term effect on access to knowledge of such an approach.

Our concerns with the DRM systems are several, but at the core, it concerns the predictable and harmful impact of having private parties -- rightholders-- determine the default rules for access to knowledge goods. DRMs are setting law not just in relation to copyright but also with regard to general consumer and competition law. It is appropriate to at least explore and consider alternative ways of regulating the DRM

\footnotetext{
${ }^{8}$ from Open Knowledge Foundation website: http://okfn.org/ok_trail/copyright.html\#id1081558620
} 
regimes, which are more consistent with notions of protecting access to knowledge goods, and have an appropriate balance, in rules that are informed by democratic debate. Our response will focus on a approach that could lead to a more balanced approach.

Before doing so, it is worth noting that rightholders aware of the consumer backlash against DRMs are seeking to distinguish between copy restriction systems and those that track usage. There is an implict asumption that while there are concerns about the former the latter are essentially benign. However no current DRM system on the market makes such a distinction. In addition tracking usages raises a number of privacy concerns, as DRMs incorporate mostly the collection and processing of personal data with the tendency to render anonymous or pseudonymous transaction in the digital environment impossible.

DRMs that are designed to generate and transmit huge quantities of data about the personal use of a product or service carry out an unprecedented level of monitoring. It's a little like having an irremovable camera owned and operated by the publisher attached to every book to monitor and record how its used and by whom. The consumer will often not be aware of these monitoring devices or the information they collect and will have no control over its use by the DRM controller

Moreover, DRMs that are entangled with intellectual consumption and which monitor user behaviour invade a sphere with sensitive personal data potentially revealing political convictions, religious or philosophical beliefs or sexual orientation.

Under the umbrella of copyright enforcement DRMs can be abused to profile consumers by collecting and reporting back personal data or data that can be linked to an individual. DRMs can therefore operate as 'spyware' which serves purposes that are different to DRMs original purpose and are harmful for consumers.

\section{A NEW APPROACH}

We would suggest there there is an alternative way to resolve access disputes that this inquiry could usefully explore.

\section{Registration of protected DRM systems}

Instead of providing automatic legal protection to DRM regimes, we propose that vendors of DRM regimes or publishers are required to first register their systems, in order to apply for protection. Only registered systems would benefit from the anti cirumvention protections under copyright law.

Regsitration would not be automatic and would involve an evaluation of the system and negotiations over features of the system to protect user rights.

For example, Adobe might apply for anti-circumvention protection for a particular version of its ebook publishing technologies. In doing so, it could be asked to explain how the DRM regime will respond to legitimate uses of the works under public (rather than private) standards for access. The legal protection would not then be forthcoming, until the regulator was satisfied that the DRM regime did not inappropriately restrict access to the work 
The DRM itself is an assertion of a contract right, and this too could be subject to review at registration. The mechanism for reviewing the terms of use of a protected DRM could be different from that involving the DRM itself. For example, public policy might not approve a DRM that would absolutely prohibit fair dealing, time shifting for television shows, or which did not allow a work to be used on alternative computer operating systems. Public policy could also insist upon a certain amount of transparency of the DRM architecture, and require interoperability.

A review at registration could also deal with concerns about overbroad DRM controls. The DRM is a lock on a copyrighted work. It is not necessary for the lock to be given broader rights than the work itself, and also not necessary for the lock to be authorized for every use of a copyrighted work, if the lock has predictable non-trivial uses which are contrary to public policy.

The legal protections on copyrighted works need not be extended to works or uses not protected by copyright, and they need not be extended in ways that are beyond that reasonably needed to protect the most important interests of the copyright owner.

The term of protection for the lock could be shorter than the term of protection for the copyrighted work itself, and the lock could be authorized in fairly limited areas, where it is truly needed to protect the core economic rights of the author and publisher, and not authorized for other areas, where there is a weak or non-existent claim that the DRM regime is needed.

Such a review system could be self-financing for example by payment of user fees.

Such a pre registration scheme could restore the balance between rightholders and users. It would stimulate public debate over the appropriate access to digital works, and motivate DRM vendors and publishers to think more constructively about reconciling the needs of publishers and end users.

We believe that as a last resort, there should be the legal right to circumvent DRM protections. This reverses the incentives which at present encourage closed systems and instead encourages compliance with copyright exemptions. E.g DRM systems lose the legal protection against anti circumvention if they stop lawful use. A circumvention right alone maybe a necessary but is not a sufficent solution, as many consumers will be unfamiliar with such tools and new control systems which are embedded in hardware such as the proposed trusted computing systems will make circumvention difficult if not impossible.

In realtion to interoperability we support limted regulatory intervention to allow interoperability. For example the French proposal for interoperability currently under discussion as they implement the Copyright Directive. There are also examples from the UK e.g the interfaces mandated for Digital TV, or mandatory interface disclosure for complimentary product manufacturers.

\section{Copyright- Orphan works}


The US Copyright Office has recently completed a wide ranging consultation on this issue, which has concluded that the problems of seeking to identify and clear the rights to orphan works is a significant problem for creators and public bodies who wish to make their collections available for example Museums and Universities. The initial conclusion is to provide a 'safe harbour' for users of orphan works. Provided a diligent search for the owner has been undertaken, if the orphan's owner later appears they can only claim reasonable compensation, but no attorney's fees or statutory damages, which are usually very high and the fear of which deters publication of orphan works. The European Commission in its recent consultation on digital libraries also asked for proposals to deal with Orphan works.

Given that any meaningful solution must apply at least to the EU and preferably globally, it may be useful for the Review to hold a public consultation on the US and EU proposals, and also to consider new ideas or ideas that were proposed by stakeholders but not yet adapted in the US debate.

\section{Parallel imports/ International Exhaustion}

CPTech is generally supportive of International Exhaustion in the areas of patents, copyrights and trademarks (subject to the important qualifications given below).

Restrictions on parallel trade can favour anti-competitive behaviour, and by facilitating global market segmentation and price discrimination, lead to high prices for UK consumers.

Trademark protection is supported by a network of 'official suppliers' which combined provide rights-holders with the ability to impose a pincer movement on retail competition by limiting the number of officially sanctioned suppliers and stopping competition from parallel importers, harming consumers. A relatively recent example of this was seen when Levi was able to prevent parallel importation by Tesco. At the time of the dispute, Levi jeans were selling retail in the US at $\$ 25$, they were sold in the UK by official suppliers at $\$ 75$ and Tesco proposed to sell for $\$ 45$. It is difficult to see the justification for using Trademark law to support such transparent price discrimination for such a good.

It is important to differentiate between counterfeiting i.e fake goods and the importation of legitimate stock but at a lower price. Trademark holders tend to conflate the two issues in order to prevent an economic analysis of the benefits of parallel trade. There are existing laws to deal with counterfeited products; it does not require the artificial straining of the purpose behind Trademarks, especially when it leads to economic damage to consumers.

The purpose of trademarks is to inform consumers about who made the product and often to signal the quality of the product and its performance. Trademarks should not give Trademark owners a 'parasitic right to interfere with the distribution of goods which bears little or no relationship to the proper function of the trademark right, 9 .

\footnotetext{
${ }^{9}$ Mr justice Laddie- Zino Davidoff Sav A\&G imports limited, CH-1998 D no 4517
} 
Opponents of International Exhaustion claim that parallel trade can lead to consumer harm associated with the selling of substandard or poorly stored goods. It would be beneficial for the Treasury to undertake an evidence-based examination of the claims made against introducing IE to feed into further discussions at the European level. Similar studies in the US by the Federal Trade Commission have shown that although authorised importers had provided anecdotal evidence of consumer injury, allegedly associated with the sale of grey market goods, there was insufficient evidence of a systematic problem to warrant an intervention.

In contrast there are real benefits to consumers. Parallel trade undermines international price discrimination; it leads to a variety of supply (servicing a market that maybe perceived as too small to warrant an official outlet, niche car markets, etc); it also encourages good service, as official status as the only supplier can lead to complacency and poor performance, competition from others means they have to 'raise their game'. It can also benefit traders who can be hit by currency fluctuations; parallel trade allows them to off load stock.

There is also a broader global policy dimension to this issue. The UK promotes free trade, globalisation and liberalisation. However restrictions on importing deprive consumers from the benefits of a global market. There is little point in promoting a single market in Europe if in essence it becomes a fortress market controlled by vested interests.

This said, CPTech does recognize there are special issues associated with certain categories of good where prices globally should consider differences in incomes. In particularly, CPTech recognizes the importance of avoiding a single world price for patented medicines, and supports a global regime that permits countries to engage in parallel trade between countries of roughly similar or higher income, but to normally prohibit parallel trade from lower income countries to higher income countries. This could be accomplished within broad categories of countries, for example, by allowing the UK to obtain imports of medicines from any countries defined as high income by the World Bank.

There may be other categories of knowledge goods that would be appropriate for a system of limited (to 'high income countries') international exhaustion. This might for example include certain entertainment goods such as computer games, recorded music or motion pictures, or certain scientific and educational materials.

\section{ADDITIONAL ISSUES}

\section{STANDARDS}

Patent policy should enable and not undermine the development of standards that promote investment and development of new knowledge goods. Standards involve particular technical approaches to important problems, including methods that can be patented. The efficient development of technical standards requires disclosure of relevant patents, and global norms for patentability that eschew trivial extensions of technological know-how in areas that create unwarranted encroachments on the public domain. Failures to require disclosure of relevant patents, or adoption of low standards of inventive step will increase transaction costs and raise private incentives 
to block new standards. When the relevant markets are global, it is no longer sufficient to address these issues in a country-by-country basis, or only within a standards making body, or even only within the European Union. CPTech recommends the UK ask WIPO to begin discussions on the management of disclosure of patent claims on proposed standards, to identify constructive measures that can address these problems in a multilateral fora.

\section{WTO Opt-Out decision.}

The European Commission made a serious mistake when it proposed that no EU Member State would ever use the 30 August 2003 WTO Decision as an importer of generic medicines, including remarkably even cases of national emergencies. This decision is not grounded upon any responsible analysis of the interests of EU Member States, and it does not recognize the mounting evidence that EU Member States will need to address cases of public interest or abuses of patent rights in situations where importing medicines from either non-Member States or even between Member States is appropriate.

\section{Further Information}

Cptech would be happy to provide additional information. Please contact in the first instance:

Michelle Childs

Head of European Affairs

Consumer Project on Technology

24 Highbury Crescent, London N5

$1 \mathrm{RX}$, e-mail michelle.childs at cptech.org 